\title{
Source side seismic tomography (3STomo): A novel method to image the subsurface structure beneath seismically active region*
}

\author{
Ting Yang ${ }^{1, \star}$ Shenyi $\mathrm{Gu}^{2}$ and Khanh Phon $\mathrm{Le}^{3}$ \\ ${ }^{1}$ State Key Laboratory of Marine Geology, Tongji University, Shanghai 200092, China \\ ${ }^{2}$ Center for Earthquake Analysis and Prediction, Earthquake Administration of Hainan, \\ Hainan 570203, China \\ ${ }^{3}$ Faculty of Oil and Gas, Hanoi University of Mining and Geology, Dong Ngac, Tu Liem, Hanoi, Vietnam
}

\begin{abstract}
We propose a novel seismic tomography method, Source Side Seismic Tomography (3STomo), which is designed particularly to image the subsurface structure beneath seismically active regions. Unlike the teleseismic tomography, in which the data are relative traveltime residuals between closely spaced stations for each teleseismic event, 3STomo uses relative traveltime shifts between earthquakes within the study region for each distant station. Given the relatively evener distribution of global seismic stations, this method has unique advantages for imaging the structure beneath regions that have numerous earthquakes but lack of dense seismic stations, for example, some subduction zones and spreading ridges in the ocean. In addition, 3STomo has potentially better vertical resolution at shallow depths than the traditional teleseismic tomography. The effect of the inaccurate source parameters on its resolution can be minimized by using depth phases and the technique of joint source and structure inversion. Numerical experiments and application to Luzon Island, Philippines show that 3 STomo can be a valuable tool to investigate the subsurface structure beneath some areas where the traditional method cannot be applied to, or at least it can be used as a complementary component of conventional teleseismic tomography to obtain better back-azimuth coverage and achieve higher resolution at shallow depths in the inversion.
\end{abstract}

Key words: seismic tomography, teleseismic tomography, subduction zone, lithosphere, Luzon Island CLC number: P315.2 Document code: A

\section{Introduction}

Seismology is a primary tool to investigate the Earth structure and its internal physical, chemical and dynamic processes (e.g., Romanowicz, 2008). In order to understand the geodynamic processes on a local or regional scale, seismologists often deploy a temporary seismic network or array covering the interested region, and a number of seismological techniques then can be employed to study its detailed subsurface structure, internal boundaries, mantle flow directions and crustal deformation properties. Such experiments have been carried out in many parts of the world by US seismologists under the program called PASSCAL (Program for

\footnotetext{
* Received 2 September 2010; accepted in revised form 8 October 2010; published 10 December 2010.

* Corresponding author. e-mail: tyang@tongji.edu.cn

(C) The Seismological Society of China and Springer-Verlag Berlin Heidelberg 2010
}

Array Seismic Studies of the Continental Lithosphere) or similar projects around the world, through which a great deal of scientific discoveries have been made and our understanding of the lithosphere and deep mantle dynamics have significantly improved (e.g., Aki et al., 1977; Wolfe et al., 1997; Yang et al., 2009).

There are many places in the world, however, that do not allow us to install seismic network or array, even temporarily. A good example is the vast deep ocean floor. Even though Ocean Bottom Seismographs (OBSs) have been existing for decades, the majority of ocean floor has never been sampled by any seismic stations because of technique difficulties and extremely high costs. This situation is believed to be the biggest challenge faced by modern seismology in order to better understand the earth interior (e.g., Lay et al., 2008). Regions that cannot deploy seismic networks also include inaccessible remote areas, geopolitically sensitive territories and more 
commonly, areas where the local governments simply do not allow seismic deployments. These regions, therefore, can not be investigated by conducting the PASSCALtype experiments, and their deep dynamic processes are poorly understood.

On the other hand, PASSCAL-type studies often require an even distribution of earthquakes. Global earthquakes, however, tend to occur along plate boundaries. Even for regions where we are able to deploy seismic networks, the distribution of earthquakes may not be favorable for such studies. During a typical deploying period of the PASSCAL experiment, which is usually one to two years, it is common that seismologists cannot obtain uniform back-azimuth coverage for their study regions, potentially leading to artifacts or misinterpretations in their investigations.

In this paper, we propose a novel seismic method, Source Side Seismic Tomography (3STomo), which is a simple alternation of the conventional teleseismic tomography. 3STomo can be used in regions where there are numerous large or moderate earthquakes but no seismic networks are available. It can also work together with the traditional tomography, to provide better back-azimuth coverage to improve the resolution.

\section{Conventional teleseismic tomography and 3STomo}

Among all seismological tools used in PASSCAL-type experiments, seismic tomography is perhaps the most important approach to study the Earth interior. Depending on the target region and the dataset used, there exist many types of seismic tomography. For example, Local Earthquake Tomography (LET) (Thurber, 1993), in which both earthquakes and seismic stations are confined to the model volume, can only image the crustal and uppermost mantle structure through which the local seismic rays propagate (e.g., Yang and Shen 2005). Another class of seismic tomography is called teleseismic tomography, which have been widely used to investigate the lithosphere and upper mantle structure. The important geodynamic processes such as subductions and mantle plumes were unraveled by this approach (e.g., Eberhart-Phillips and Reyners, 1997; Zhao et al., 1997; Wolfe et al., 1997; 2009; Yang et al., 2009). The proposed 3STomo is an alternation of the teleseismic tomography. To better understand this new method, its advantages and limitations, we first recount the details of the conventional teleseismic tomography.

\subsection{Teleseismic tomography}

While the target volume in teleseismic tomography is the lithosphere and upper mantle beneath the seismic array, earthquake sources used in this study, by definition, are teleseismic events, which are generally thousands of kilometers away from the receiver array (Figure 1a). Teleseismic tomography is able to achieve this goal because it assumes only heterogeneities beneath the receiver array affect the traveltime residuals. Velocity anomalies outside the target volume and errors in hypocenter locations and origin times contribute little if any to the observed residues. This assumption can be justified because of the fact that teleseismic tomography uses relative traveltime residual between two closely spaced stations rather than the absolute traveltime of each station. The effect of near-source and deep-mantle anomalies, therefore, is negligible since those portions of the ray paths are virtually identical between two closely spaced stations (Figure 1) (e.g., Aki et al., 1977; Humphreys and Clayton, 1984; VanDecar and Crosson, 1990). The earthquake mis-location and error in origin time are simply cancelled out from relative traveltime residuals.

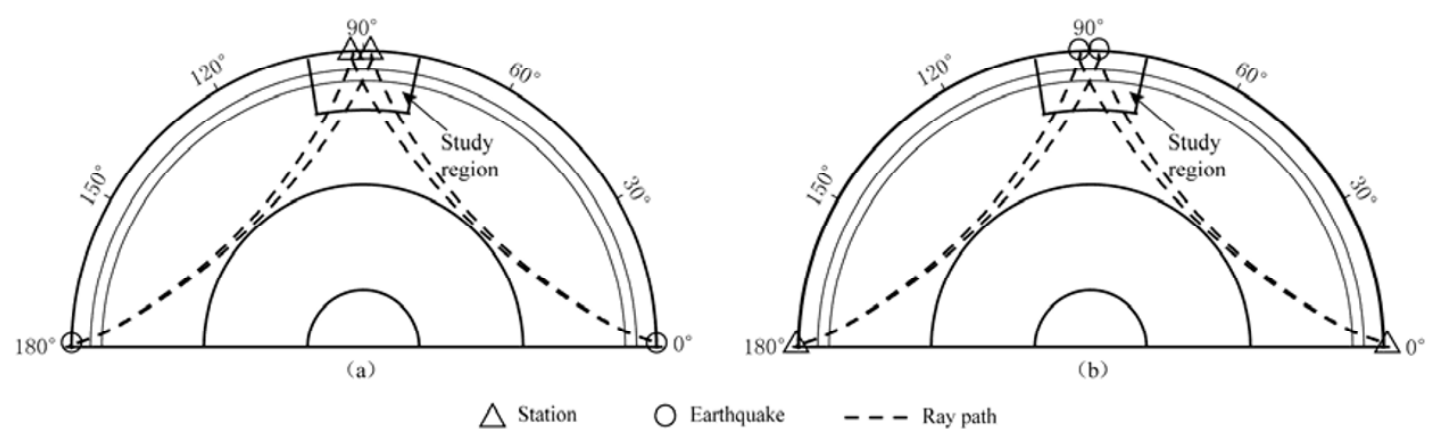

Figure 1 A schematic comparison of the conventional teleseismic tomography (a) and Source Side Seismic Tomography (3STomo) (b). Note that the most portions of the two ray paths in both methods are virtually identical. 
Depending on station intervals and the aperture of seismic array, teleseismic tomography can presumably achieve tens of kilometer resolution capacity from the Earth surface to about several hundred kilometers deep. However, since incoming rays from teleseismic events are nearly vertical beneath the receiver array, this technique has excellent horizontal resolution but the vertical resolution is often less than ideal, particularly at depths less than $100 \mathrm{~km}$ (e.g., Keller et al., 2000). Vertical velocity variations at shallow depths are often poorly constrained and therefore must be interpreted with caution (Leveque and Masson, 1999). The widely used remedy is to add extra constraints, for example, combining teleseismic tomography with LET (e.g., Zhao et al., 1994; Bijwaard et al., 1998) or surface wave study (e.g., Allen et al., 2002) to obtain the structure from the Earth surface to deep mantle.

One long-standing difficulty in teleseismic tomography is the irregular distribution of global earthquakes. Earthquakes tend to occur along plate boundaries, and most moderate and large earthquakes occur in or near subduction zones, which, in many regions in the world, restricts the back-azimuth coverage for the tomographic studies (Figure 2a). To make this situation worse, in body wave teleseismic tomography, only earthquakes with epicentral distances in the range from $30^{\circ}$ to $90^{\circ}$ can be selected as useful sources because events outside this range, either will generate triplicated waves sampling in the transition zone or the core-mantle boundary, which poses difficulties to determine raypaths for arrival phases, or contribute little to the depth resolution due to their completely vertical ray paths (core phases). Thus, it is not uncommon, for many regions in the world, to have very uneven distribution of ray paths (in terms of back-azimuth and inclination) through the target volume in teleseismic tomography. The unevenly distributed earthquakes in tomography could cause strong streakings and artifacts in the resulting images, which may be responsible for many misinterpretations such as "plumelike" or "tilted" structures in tomographic models.

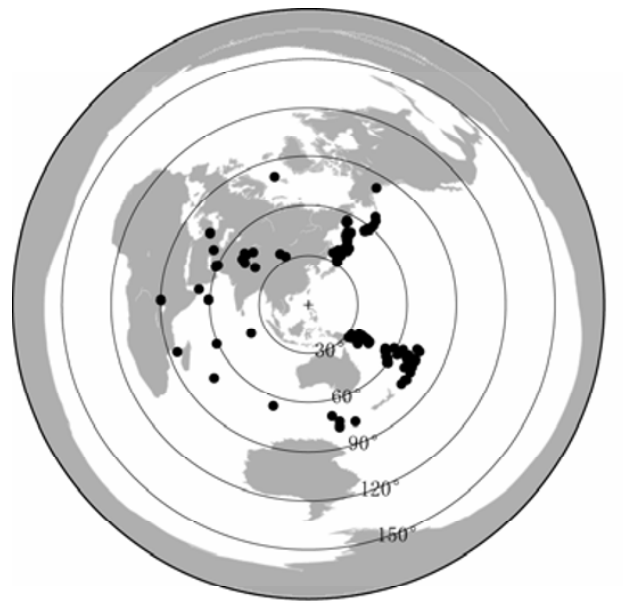

(a)

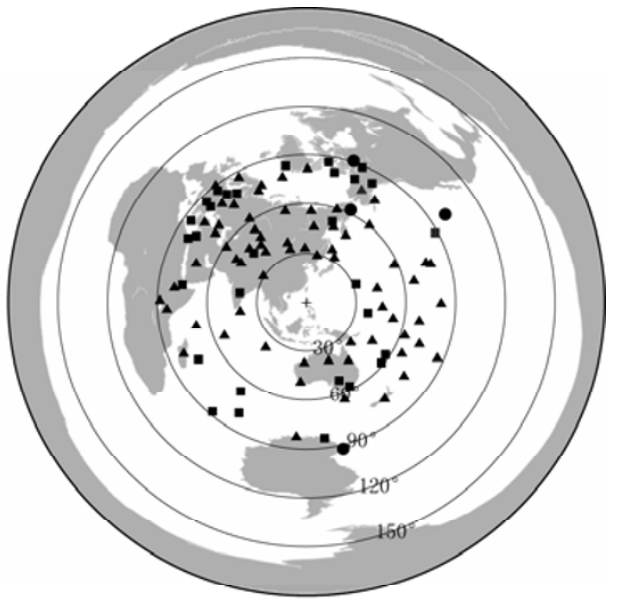

(b)

Figure 2 A comparison of the global earthquake distribution (a) and the global seismic station distribution (b) in the epicentral distance range from $30^{\circ}$ to $90^{\circ}$ centered at Luzon Island, Philippines. Earthquakes in (a) occur at the period of July 2007 to December 2008 , with magnitude great than 5.5. Please note that there are large back-azimuth gaps caused by uneven seismicity distribution and limited deployment period. Stations shown in (b) are also ones used in this study.

\subsection{Source Side Seisnifiemography (3STomo)}

The 3STomo is an alternation of the teleseismic tomography. The concept is quite simple and straight forward. As illustrated in the Figure 1, 3STomo simply interchanges the roles of stations and earthquakes played in conventional teleseismic tomography. The target volume then becomes regions beneath earthquakes; and stations are located far away from the target volume in 3STomo. Accordingly, the data used in 3STomo are re- siduals between earthquakes relative to a distant station. Heterogeneities on the station side and in the deep mantle, therefore, have negligible effects on the relative traveltime residuals between two closely spaced events. If a region has active seismicity, especially scattered moderate and large earthquakes, its subsurface structure can be resolved by this method. These regions include, but not limited to, some subduction zones, mid-ocean ridges in the ocean. 
In addition to the ability to resolve the structure beneath regions having no dense stations, 3STomo has two advantages over the conventional tomography. In the first, the distribution of the global seismic stations is evener than large earthquakes during the typical duration of a portable seismic array experiment (one to two years) (Figure 2). As a result, the back-azimuth coverage should be better in 3STomo. Second, unlike seismic stations, which have to be installed at the Earth surface, earthquakes occur at various depths. If we include events with different source depths in the inversion, they could provide another way to constrain vertical variations of the shallow structure, where the conventional tomography has poor resolving power (Leveque and Masson, 1999).

Despite of its advantages, 3STomo also has an important drawback compared with the traditional tomography, that is, errors in source parameters can no longer be cancelled out in 3STomo. Instead, they will go into residuals, and cannot be easily distinguished from the structure anomalies. With several sophisticated earthquake location methods emerged (e.g., Engdahl et al., 1998; Waldhauser and Ellsworth, 2000), however, this problem can be addressed by (1) using the depth phases, $\mathrm{pP}, \mathrm{pS}, \mathrm{sP}$ etc, which are abundant for deep earthquakes in subduction zones; (2) the joint inversion, through which the heterogeneities and the source parameters are inverted simultaneously. These two methods can be used in 3STomo to minimize the effect of source errors.

\section{Application to the Luzon Island, Philippines}

The Luzon Island, Philippines is tectonically unique in that it is underlain by two opposing subductions and a major transform fault across the Island. Despite its high seismicity, the subsurface characteristics of both subducting slabs, South China Sea plate and Philippine Sea plate, were poorly constrained in previous studies due to the lack of a dense seismic array. As a result, there exist several puzzling surface features regarding its volcanism and seismicity, including the temporal and spatial distribution of volcanoes, seismic gaps and untypical focal mechanisms (e.g., Yang et al., 1996; Bautista et al., 2001). The seismicity in Luzon Island is very high, with about $40 M>5.0$ earthquakes per year. Since the two subductions situate two sides of the Island and the major transform fault in the middle, earthquakes in Luzon are evenly distributed. Figure $4 \mathrm{a}$ shows selected 250 earthquakes with magnitude greater than 5.3 from 2000 to 2007 in this area, which are also earthquake used in this study.

The traveltime data and the source parameters used in this study were from EHB catalogue, which is believed to be the most accurate catalogue available because they re-located all sources using additional phases such as depth phases and corrected many errors in phase identifications (Engdalh et al., 1998). Selected global stations within epicentral distance range from $30^{\circ}$ to $90^{\circ}$ are shown in the Figure $2 \mathrm{~b}$. Note that the back-azimuth coverage is significantly improved compared with the distribution of global earthquakes (Figure 2a), which would be the sources if we conduct a conventional teleseismic tomography in this region. We selected $17562 \mathrm{P}$ phases and $4376 \mathrm{pP}$ phases from over 35000 travel time residuals in EHB catalogue as our dataset.

The subsurface structure beneath the region of study was parameterized by a $3-\mathrm{D}$ grid $(33 \mathrm{~km} \times 51$ $\mathrm{km} \times 37 \mathrm{~km}$ ) centered at $16.5^{\circ} \mathrm{N}, 121^{\circ} \mathrm{E}$, and with a dimension of $11^{\circ}$ in longitude, $16^{\circ}$ in latitude, and $800 \mathrm{~km}$ in the vertical direction. Our starting model is the 1-D radially symmetric IASP91 model (Kennett and Engdahl, 1991), and the linearized ray theory is utilized to represent traveltime shifts relative to the starting model. The inversion of the matrix is approximated using the LSQR algorithm (Paige and Saunders, 1982). To stabilize the inversion, we applied Laplace smoothing regularization as well as norm damping. We also performed a trade-off analysis of model norm versus variance reduction to determine the damping factor and the smoothing weight. With the selected values for the damping and smoothing, the inversion achieved a variance reduction of $65 \%$.

To determine the resolution of this 3STomo inversion, we conducted checkerboard resolution tests in which synthetic traveltimes were calculated for the actual event-station pairs based on an input model that contains alternating anomalies of high and low velocities. These synthetic data were inverted in the same manner as was done in the actual inversion. Gaussian noise with a standard deviation of $50 \mathrm{~ms}$ was added to the synthetic traveltime residuals prior to inversion. Figure 3 shows the results for one such test. The input anomalies with dimension of $90 \mathrm{~km} \times 90 \mathrm{~km} \times 75 \mathrm{~km}$ were well recovered to depths of about $480 \mathrm{~km}$. The edges of our target regions and depths greater than $500 \mathrm{~km}$ are not well resolved and show slight streakings because of the lack of crossing raypaths.

Our preliminary $\mathrm{P}$-wave velocity model beneath 

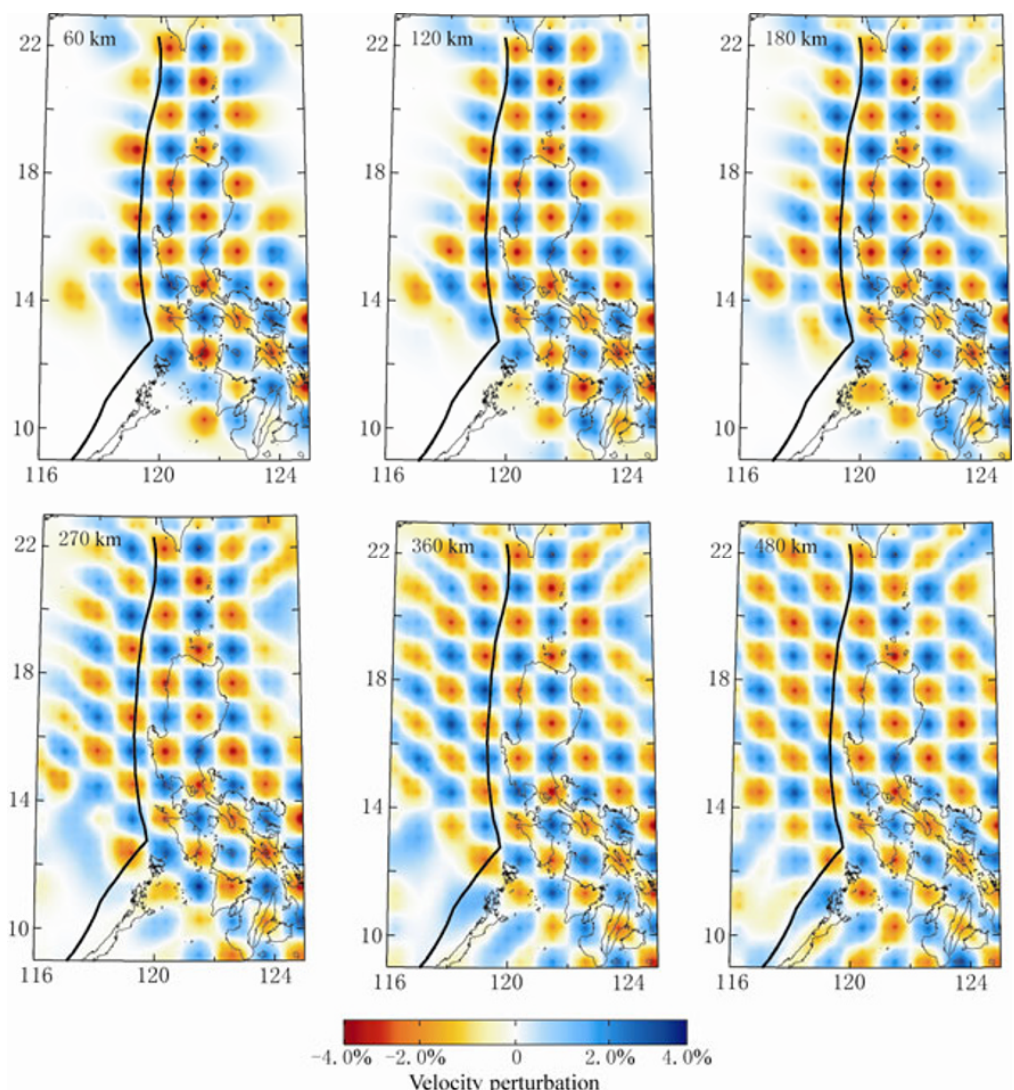

Figure 3 Resolution test. The input synthetic model is a sinusoidal checkerboard with the maximum amplitude of the perturbation being $4 \%$ (block size are $90 \mathrm{~km} \times 90 \mathrm{~km}$ ). Gaussian noise with a standard error of $50 \mathrm{~ms}$ was added to the synthetic traveltimes. Please note the shallow anomalies are well resolved.

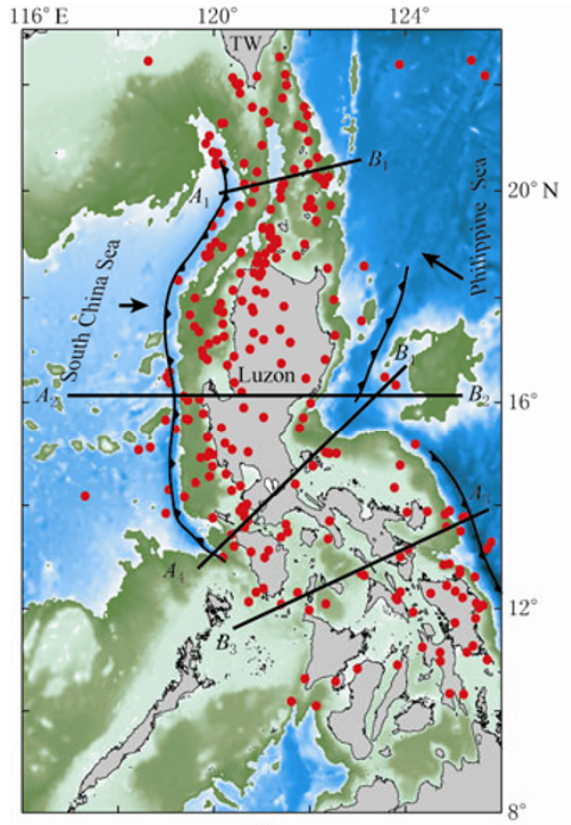

(a)
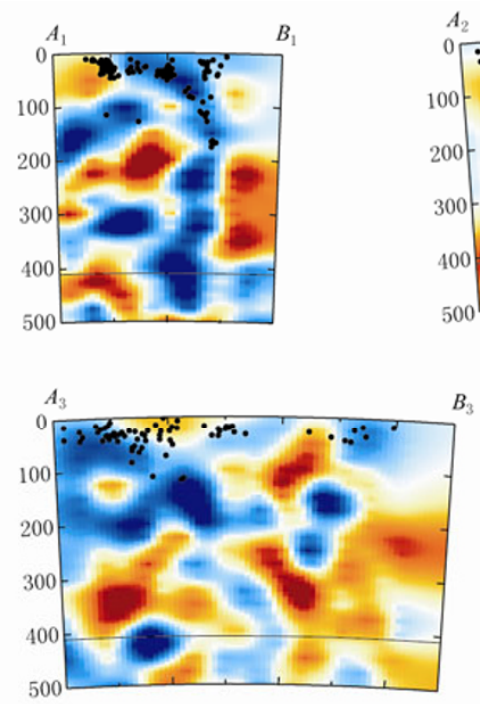

$A_{4}$

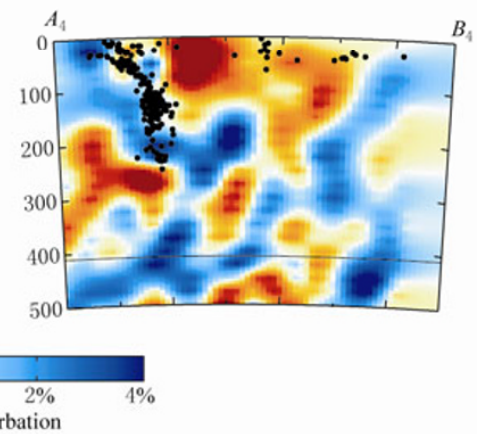

(b)

Figure 4 The preliminary P-wave velocity model from 3STomo plotted along four vertical cross-sections. The main tectonic units in the study region, earthquakes used in this study and the cross-section locations are shown in (a). The black dots in each section are local earthquakes within a 100-km perpendicular distance from the cross-section lines. 
Luzon Island from the 3 STomo is shown in Figure 4. In this study we assume source parameters are accurate because the relocated EHB catalogue was used. Four cross-sections perpendicular to the trench line are shown in the figure, along with the projected local seismicity within $100 \mathrm{~km}$ perpendicular distance from the profile lines. As we can see from the profiles, the general geometric features of both South China Sea plate and Philippine Sea plate were revealed; and they are roughly consistent with neighboring earthquake distributions. However, there are some distortions on the slabs, which may be attributed to inaccurate locations of some earthquakes used in the version. Nevertheless, there are several evident features worthy pointing out. On cross section $A_{1}-B_{1}$, which sits above the Bashi strait, the slab-like high velocity anomaly extends nearly vertically to $500 \mathrm{~km}$ depth, and even slightly overturned in the deep. This geometry may suggest that, in that area, the subduction of South China Sea plate was hampered by opposing motion of the Philippine Sea Plate. There exists a broad low velocity body on cross section $A_{2}-B_{2}$ in the $200 \mathrm{~km}$ to $300 \mathrm{~km}$ depth range, which connects with two detached shallow low velocity anomlies. This section traverses the subducting location of the extinct ridge of South China Sea, and is perpendicular to the two paralleled volcanic arcs at surface (Yang et al., 1996). It is possible that, therefore, this low velocity anomaly is the mantle materials upwelling through the window opened by the subducted ridge, as proposed in models of Yang et al. (1996) and Bautista et al. (2001), with the detached shallow anomalies being the subsurface sources for the two paralleled volcanic arcs. In addition, on cross section $A_{3}-B_{3}$, the Philippine Sea plate also shows slab-like subduction features extending to at least $200 \mathrm{~km}$ depth. This feature contradicts with previous study from seismicity indicating that this portion of subduction has no defined Wadati-Benioff zone (Galgana et al., 2007).

\section{Discussion}

As mentioned above, the biggest challenge for the new 3STomo is uncertainties or errors of the source parameters, which could directly affect the structure inversion. Although we can use other constraints and techniques to address this problem, it is not easy to assess their influence on the inversion, casting doubt on the resultant images of tomography. Nevertheless, 3STomo has its advantages over teleseismic tomography, and can be used to certain regions where the traditional way cannot be applied to.

3STomo is not the only tomographic method having this problem. The widely used LET is also required to invert the hypocenter and the structure jointly. The LET is still seen as a valid approach because it relocates earthquakes on a local scale using a local network, which can presumably yield more accurate results than that at teleseismic distances. In some special cases, 3STomo can also be applied to in the same way as the LET, as long as there are stations in the study region, to relocate earthquakes on a local scale in the inversion. It is common that an area has some stations, but is not suited for the traditional tomographic study because the number of stations may be not enough, or the station intervals are too sparse. In addition, for PASSCAL-type experiments, in which the study regions usually have dense stations, the common difficulty of poor back -azimuth coverage can also be tackled by relocating earthquake through local network in 3STomo. In these applications, we can use the local network to relocate earthquakes in the 3STomo, and combine the stations and earthquake in the study region to fill the gaps left by poor back-azimuth coverage or sparse station intervals, that is, using the 3 STomo as a complementary component of the traditional teleseismic tomography to obtain evener and higher resolution.

\section{Conclusions}

The Source Side Seismic Tomography (3STomo) is a simple alternation of the conventional teleseismic tomography, designed particularly to image the subsurface structure beneath seismically active regions. Advantages of 3STomo over the traditional teleseismic tomography include evener back-azimuth coverage and potentially higher resolution in the shallow structure. On the other hand, uncertainties or errors in source parameters put limitations to this new method, although their effect on the structure can be minimized by using depth phases in subduction zones or the technique of joint inversion. However, in some special cases 3STomo could still be a valuable tool to investigate the subsurface structure beneath seismically active regions where (1) there is no any station and the traditional teleseismic tomography can not be applied to; (2) stations are not enough, or station intervals are sparse; (3) the back-azimuth coverage is poor for a conventional teleseismic tomography, even the station distribution is good. In the last two cases, earthquakes can be relocated by local stations in the inversion; and 3STomo can be used as a comple- 
mentary component of teleseismic tomography, achieving better resolution in the inversion.

Acknowledgements The authors thank Prof. John Chen for inviting us to contribute to this special issue. Financial supports for this study were provided by the National Natural Science Foundation of China granted No.41076019 and the Program 973 through grant 2007CB411702. T. Yang was also partially supported by the Shanghai Pujiang Program and the Innovation Program of Shanghai Municipal Education Commission. We also thank two anonymous reviewers whose comments greatly improved the manuscript.

\section{References}

Allen R M, Nolet G, Morgan W J, Vogfjord K, Bergsson B H, Erlendsson P, Fouger G R, Jakobsdottir S, Julian B R, Pritchard M, Ragnarsson S and Stefansson R (2002). Imaging the mantle beneath Iceland using integrated seismological techniques. J Geophys Res 107: 2325, doi: 10.1029/2001JB000595.

Aki K, Christoffersson A and Huesbye E S (1977). Determination of the three-dimensional structure of the lithosphere. $J$ Geophys Res 82: 277-296.

Bautista B C, Bautista M L P, Oike K, Wu F T and Punongbayan R S (2001). A new insight on the geometry of subducting slabs in northern Luzon, Philippines. Tectonophys 339: 279-310

Bijwaard H, Spakman W and Engdahl E R (1998). Closing the gap between regional and global travel time tomography. $J$ Geophys Res 103: 30 055-30078.

Eberhart-Phillips D and Reyners M (1997). Continental subduction and three-dimensional crustal structure: The northern South Island, New Zealand. J Geophys Res 102: 11 84811861.

Engdahl E R, van der Hilst R and Buland R (1998). Global teleseismic earthquake location with improved travel times and procedures for depth determination. Bull Seismol Soc Am 88: $722-743$.

Galgana G, Hamburger M, McCaffrey R, Corpuz E and Chen Q (2007). Analysis of curstal deformation in Luzon, Philippines using geodetic observations and earthquake focal mechanism. Tectonophys 432: 63-87, doi: 10.1016/j.tecto.2006.12.001.

Humphreys E D and Clayton R W (1990). Tomographic image of the Southern California Mantle. J Geophys Res 95: $19725-$ 19746.

Keller W R, Anderson D L and Clayton R W (2000). Resolution of tomographic models of the mantle beneath Iceland. Geophys Res Lett 27: 3993-3 996.

Kennett B L N and Engdahl E R (1991). Traveltimes for global earthquake location and phase identification. Geophys $J$ Int 105: 429-465.
Lay T, Forsyth D W, Aster R C, Romanowicz B, Allen R M, Cormier V F, Gomberg J, Hole J A, Masters G, Schutt D, Sheehan A, Tromp J, Wysession M E (2008). Seismological grand challenges in understanding Earth's dynamic systems. Report of long-range science plan for seismology workshop, Sep 18-19, Denver, Co.

Leveque J J and Masson F (1999). From ACH tomographic models to absolute velocity models. Geophys J Int 137: 621-629.

Paige C C and Saunders M A (1982). LSQR: An algorithm for sparse linear equations and sparse least squares. ACM Trans Math Softw 8: 43-71.

Romanowicz B (2008). Using seismic waves to image Earth's internal structure. Nature 451: 266-268.

Thurber C H (1983). Earthquake locations and three-dimensional crustal structure in the Coyote Lake area, central California. $J$ Geophys Res 88: 8226-8236.

VanDecar J C and Crosson R S (1990). Determination of teleseismic relative phase arrival times using multi-channel cross-correciton and least squares. Bull Seismol Soc Am 80: $150-169$.

Waldhauser F and Ellsworth W L (2000). Double-difference earthquake location algorithm: Method and application to the northern Hayward fault. Bull Seismol Soc Am 90: 1 3531368.

Wolfe C J, Bjarnason I Th, VanDecar J C and Solomon S C (1997). Seismic structure of the Iceland mantleplume. Nature 385: 245-247.

Wolfe C J, Solomon S C, Hauri E H, Laske G, Orcutt, Collins J A, Detrick R S and Bercovici D (2009). Mantle shear-wave velocity strucuture beneath the Hawaiian hot spot. Science 326: 1388-1390.

Yang T and Shen Y (2005). P-wave velocity structure of the crust and uppermost mantle beneath Iceland from local earthquake tomography. Earth Planet Sci Lett 235: 597-609.

Yang T, Grand S P, Wilson D, Guzman-Speziale M, Gomez-Gonzalez J M, Dominguez-Reyes T and Ni J (2009). Seismic structure beneath the Rivera subduction zone from finite-frequency seismic tomography. $J$ Geophys Res 114: B01302, doi: 10.1029/2008JB005830.

Yang T F, Lee T, Chen C-H, Cheng C-H, Knittel U, Punongbayan R S and Rasdas A R (1996) A double island arc between Taiwan and Luzon: consequence of redge subduction. Tectonophys 258: 85-101.

Zhao D, Hasegawa A and Horiuchi S (1992). Tomographic imaging of $\mathrm{P}$ and $\mathrm{S}$ wave velocity structure beneath Northeastern Japan. J Geophys Res 97: 19 909-19928.

Zhao D, Hasegawa A and Kanamori H (1994). Deep structure of Japan subduction zone as derived from local, regional, and teleseismic events. J Geophys Res 99: 22 313-22 329.

Zhao D, Xu Y, Wiens D, Dorman L, Hildebrand J and Webb S (1997). Depth extent of the Lau back-arc spreading center and its relation to subduction processes. Science 278: 254-257. 